\title{
Acolhimento familiar: caracterização de um programa ${ }^{1}$
}

\author{
Lara Barros Martins ${ }^{2}$ \\ Nina Rosa do Amaral Costa \\ Maria Clotilde Rossetti-Ferreira \\ Universidade de São Paulo, Ribeirão Preto-SP, Brasil
}

\begin{abstract}
Resumo: Este artigo objetiva caracterizar os principais atores envolvidos em um programa de Acolhimento Familiar e os acolhimentos realizados. Esse programa efetuou 314 acolhimentos entre 1998 e 2007. Neste período, a maioria dos acolhidos eram meninos $(51,7 \%)$, afrodescendentes $(55,3 \%)$, de até seis anos $(58,7 \%)$. As famílias acolhedoras eram constituídas por casais (70,4\%), com filhos (84,1\%); faixa etária entre 30 e 49 anos; bom nível de escolarização; profissões autônomas; rendas diversificadas e motivações solidárias para acolher. Com relação às famílias de origem não foram encontradas informações. Como principal causa dos acolhimentos foi citada a negligência (33,7\%). Sua duração foi de um a seis meses em $46,65 \%$ dos casos. Quanto aos encaminhamentos pós-acolhimento, 34,2\% das crianças foram adotadas e 33,8\%, reintegradas às suas famílias. Caracterizar um programa oferece subsídios para a redefinição de práticas e auxilia na formulação de ações de intervenção em situações complexas como o acolhimento familiar.
\end{abstract}

Palavras-chave: infância, adolescência, família, políticas públicas.

\section{Foster care: program characterization}

\begin{abstract}
This paper aims to describe the main actors involved in a Foster Care program and its processes. The program had done 314 fosterings from 1998 to 2007. During this period, most foster children were boys $(51,7 \%)$, afrodescendants (55,3\%), aged up to 6 years old $(58,7 \%)$. Foster families were formed by couples $(70,4 \%)$, with other children $(84,1 \%)$; aged from 30 to 49 years old; good education level; autonomous professions; diversified incomes and solidarity motivation to foster. No registered information about the biological families was found. The principal reason referred to for fostering was negligence $(33,7 \%)$. The child remained in foster care from 1 to 6 months in 46,65\% cases. Regarding the outcome of the fostering process, $34,2 \%$ children were adopted and $33,8 \%$ were reintegrated into their families. Describing a program helps to redefine practices and to discuss measures of intervention for the area.
\end{abstract}

Keywords: childhood, adolescence, family, public policies.

\section{Acogimiento familiar: caracterización de un programa}

Resumen: El artículo objetiva conocer los principales envueltos en un programa de Acogimiento Familiar y los acogimientos realizados. Ese programa efectuó 314 acogimientos entre 1998 y 2007. En ese período, la mayoría de los acogidos eran niños $(51,7 \%)$, afrodescendientes $(55,3 \%)$, hasta 6 anõs $(58,7 \%)$. Las familias acogedoras eran constituidas por parejas $(70,4 \%)$, con hijos (84,1\%); edad entre 30 y 49 años; buen nivel de escolaridad; profesiones autónomas; ingresos diversificados y motivaciones solidarias para acoger. Sobre las familias de origen no fueron encontradas informaciones. La principal causa de los acogimientos fue la negligencia (33,7\%), y su duración de 1 a 6 meses in 46,65\% de los casos. Sobre las derivaciones de los acogimientos, $34,2 \%$ de los niños fueran adoptados y $33,8 \%$, regresaron a sus familias. Describir un programa ofrece subsidios para la redefinición de prácticas y puede auxiliar a repensar acciones de intervención en el área.

Palabras clave: infancia, adolescencia, familia, políticas públicas.

No Brasil, o acolhimento e cuidado das crianças e adolescentes que vivenciavam situações de abandono ou orfandade tornaram-se uma questão pública, de preocupação da sociedade civil, apenas em meados do século XIX, momento em que ocorreu o incremento dos mecanismos de

\footnotetext{
${ }^{1}$ Apoio: FAPESP e CNPq. Este artigo é derivado da Iniciação Científica da primeira autora, sob a orientação da terceira, no Programa de Bacharelado Especial em Pesquisa do curso de Psicologia da Faculdade de Filosofia, Ciências e Letras de Ribeirão Preto da Universidade de São Paulo. Este texto foi revisado segundo Acordo Ortográfico da Língua Portuguesa (1990), em vigor a partir de $1^{\circ}$ de janeiro de 2009.

${ }^{2}$ Endereço para correspondência:

Lara Barros Martins. Universidade de São Paulo. Faculdade de Filosofia, Ciências e Letras de Ribeirão Preto. Departamento de Psicologia e Educação. CINDEDI. Av. Bandeirantes, 3900, Monte Alegre, CEP 14.040901. Ribeirão Preto-SP, Brasil._E-mail: lara_bmartins@hotmail.com.
}

acolhimento já existentes, como as instituições asilares (orfanatos) e a "Roda dos Expostos". As Rodas, instauradas nas Santas Casas de Misericórdia, recebiam as crianças ali abandonadas que eram enviadas para amas de leite mercenárias, as quais se encarregavam de seus cuidados e recebiam pagamento pela sua criação. Aquelas crianças que sobreviviam à criação das amas, aos três anos, eram devolvidas às instituições para que essas acabassem de criá-las. As instituições tinham um regime claustral, comportavam divisões por sexo, etnia e origem de seus internos, que tinham pouca ou nenhuma convivência comunitária (Marcílio, 1993; Rizzini, 1993).

Tais medidas constituíram um importante sistema de amparo e proteção à infância, mas comportavam também histórias de maus tratos e abuso dos cuidadores, além de altas taxas de mortalidade infantil e um processo de orfanização das crianças abandonadas (Rizzini \& Rizzini, 2004). 
Entretanto, paralelo ao acolhimento institucional, o acolhimento informal de crianças e adolescentes desvalidos por famílias não consanguíneas também ocorria, configurando-se uma experiência bastante antiga e comum em muitas sociedades. Nas casas de famílias mais abastadas, as amas também se encarregavam dos filhos de criação, que eram acolhidos voluntariamente por uma família disposta a lhe dedicar cuidados e que, muitas vezes, desenvolvia um vínculo socioafetivo com o acolhido (Brasil, 2004; Franco, 2000). Muitas crianças e adolescentes foram criados em casas de parentes ou junto a pessoas com as quais não possuíam laços consanguíneos, mas eram ligadas por relações de compadrio, caracterizando um tipo informal de acolhimento em contexto familiar.

Tal prática cultural, no Brasil, marca uma tradição histórica em classes populares, sendo amplamente utilizada pela sociedade civil e também pelo poder público. A inserção de uma criança em um arranjo familiar diferente do seu, acontecia sem regulamentação e critérios no país, configurando uma iniciativa voluntária da própria família biológica ao delegar o papel parental à outra família ou instituição provisoriamente, tendo em alguns casos motivos emergenciais (Brasil, 2004; Fonseca, 1995; Franco, 2000). Essa modalidade de acolhimento funciona como uma rede de apoio familiar, na qual a família extensa ou outros adultos próximos, dentro do grupo de referência dos pais, se responsabilizam pela criação e cuidados dos filhos de seus parentes ou conhecidos. Há uma transferência de atribuições à rede mais ampla, assim como um deslocamento de papéis familiares que pode viabilizar a sobrevivência da família que enfrenta dificuldades, pois the são oferecidas sustentações básicas e apoio à criança implicada (Fonseca, 1995; Sarti, 1996).

A criança é acolhida pelos familiares quando os pais biológicos não podem, não querem, ou não conseguem se encarregar de seu cuidado e educação, por apresentarem problemas de diferentes dimensões relacionados a questões econômicas, sociais e/ou de saúde. São casos em que a criança se encontra em situações de adversidade e vulnerabilidade, por estar sujeita a maus tratos, negligência severa, drogadição ou alcoolismo de seus cuidadores, entre outras causas. Esse tipo de acolhimento relaciona-se ao processo de circulação de crianças, relatado por Fonseca $(1995,2002)$ através de vários casos em que crianças passavam parte da infância ou juventude em casas que não eram a de seus genitores. Dentro do grupo de parentesco, ou até mesmo fora da rede consanguínea, existe uma coletivização das responsabilidades pelas crianças e ocorrem rearranjos para garantir subsídio financeiro e cuidado das mesmas. Sarti (1996) argumenta que a circulação de crianças faz parte do conjunto de obrigações morais que caracterizam as práticas populares.

O acolhimento realizado em famílias extensas é uma alternativa que tem sido amplamente empregada há tempos, pelo fato de contar com o apoio destas famílias e necessitar de menor esforço profissional e gasto econômico por parte das administrações públicas. Além de ser, em muitas situações, uma boa opção para manter a criança próxima de sua família e em seu contexto comunitário (Amorós \& Palacios, 2004).

A existência de uma cultura informal de acolhimento de crianças e adolescentes dá substrato para se discutir ações alternativas de proteção à infância e juventude, que considerem tais práticas e promovam outros modelos de assistência junto àqueles que se encontram em situações de vulnerabilidade e violação de seus direitos e que ingressam na rede de proteção.

\section{Acolhimento familiar}

O Acolhimento Familiar, como um programa formal, surgiu como prática alternativa à institucionalização. Segundo Cabral (2004), ele teve início em diferentes momentos em países como nos Estados Unidos em 1910, na Inglaterra em 1940, na Espanha em 1970 e na Itália em 1980, compondo políticas sociais influenciadas por uma literatura das áreas médica e psicológica (que aborda os riscos causados ao desenvolvimento infantil pela institucionalização) e por modificações ocorridas em legislações a partir de extensas discussões sobre os direitos da criança. Figura nesse cenário como normativa fundamental a Convenção sobre os Direitos da Criança (ONU, 1989), a qual atenta para a necessidade de proteção e cuidados especiais, inclusive proteção legal apropriada que se deve dedicar à criança, considerando sua condição peculiar de desenvolvimento.

As pesquisas científicas relativas à institucionalização, as mudanças legislativas, assim como o relato de experiências dos países em que o acolhimento familiar acontece como medida de proteção à criança, têm influenciado o Brasil a pensar alternativas e adotar novos modelos de suporte às crianças que ingressam na rede de proteção.

$\mathrm{Na}$ Espanha, várias questões contribuíram para a discussão e implementação do acolhimento familiar. Podem ser citadas: a mudança de seu próprio conceito, ampliando o acolhimento para outras modalidades além do acolhimento pré-adotivo; a alteração dos papéis dos acolhedores e das atitudes dos profissionais; as modificações legislativas, tendo destaque a Lei Orgânica 1/1996 de Proteção Jurídica do Menor; e as experiências do programa "Familias Canguru", iniciado em 1997. Tal programa propunha-se a ajudar a resolver problemas de crianças que deviam ser separadas de suas famílias, e que tanto a opção de institucionalização quanto a de adoção eram consideradas inadequadas, tendo em vista a possibilidade de retorno da criança à sua família de origem. A partir dessa perspectiva, foram criadas novas modalidades de acolhimento familiar, denominadas acolhimento de urgência-diagnóstica, acolhimento simples, acolhimento permanente ou acolhimento pré-adotivo, que seguem funcionando atualmente (Amorós \& Palacios, 2004).

A experiência do acolhimento familiar na Cataluña mostra que as necessidades da infância atendidas pelo Sistema de Proteção Espanhol foram se diversificando, o que tornou as alternativas de internação e adoção inadequadas, 
possibilitando a criação de um programa que considerasse essa nova demanda. Há mais de 25 anos em funcionamento, o acolhimento familiar é a medida mais utilizada nessa província espanhola (Martí \& Peláez, 2004).

Há o exemplo também dos países de língua inglesa, nos quais o acolhimento familiar tem como princípio a colocação de uma criança em família temporária que, na maioria das vezes, não tem relação de consanguinidade com a criança. Essas famílias operam com os deveres de um guardião legal (Brasil, 2004).

Outro aspecto a se considerar, é que o acolhimento familiar se adequa ao que está preconizado em normativas internacionais sobre os direitos da criança e do adolescente, como também a legislação nacional sobre o assunto. Assim, a Convenção sobre os Direitos da Criança (ONU, 1989) ratificada pelo Brasil em 1990 - trata em seus artigos oitavo e nono sobre a necessidade de ser respeitada a cultura e identidade da criança e preservar seus vínculos com a família de origem (Luna, 2004). Zela também pela proteção especial dedicada à infância, ao desenvolvimento individual e social integral da criança, compartilhando de muitos princípios que foram inseridos no Estatuto da Criança e do Adolescente [ECA] (Lei No. 8.069, 1990) quando da sua elaboração. Dessa forma, o acolhimento familiar propõe ações condizentes com os princípios defendidos por tais normas, priorizando o benefício e a proteção da população atendida pela modalidade, ao atentar para as demandas e necessidades relativas ao seu desenvolvimento.

O ECA, ao adotar a doutrina da proteção integral à criança e ao adolescente prevê, dentre outros, o direito à convivência familiar e comunitária:

Art. 19. Toda criança ou adolescente tem direito a ser criado e educado no seio da sua família e, excepcionalmente, em família substituta, assegurada a convivência familiar e comunitária, em ambiente livre da presença de pessoas dependentes de substâncias entorpecentes (Lei No. 8.069, 1990).

O artigo citado prevê a manutenção da criança ou adolescente em ambiente familiar. Em situações extremas e graves, em que a família de origem enfrenta sérios problemas, a criança pode ser encaminhada a uma família substituta, podendo ser esta uma família acolhedora responsável pelo cuidado temporário da criança em situação de risco.

No Brasil, a Política Nacional de Assistência Social (Ministério do Desenvolvimento Social e Combate à Fome, 2004), proposta pelo Ministério do Desenvolvimento Social e Combate à Fome (MDS) e Secretaria Especial de Direitos Humanos (SEDH) e aprovada pelo Conselho Nacional de Assistência Social (CNAS), prevê modalidades de atendimento assistencial destinadas a atender famílias que se encontram em situação de risco pessoal e social, sendo que os programas de acolhimento familiar aparecem como serviços de proteção social especial de alta complexidade, por garantirem proteção integral (moradia, alimentação, higienização e trabalho protegido) aos seus usuários. A proteção social especial prioriza novas modalidades de atendimento, visando à reestruturação de serviços de abrigamento.

Também o Plano Nacional de Promoção, Proteção e Defesa do Direito de Crianças e Adolescentes à Convivência Familiar e Comunitária (2006) - elaborado pelo Ministério do Desenvolvimento Social e Combate à Fome (MDS), Secretaria Especial de Direitos Humanos (SEDH), Conselho Nacional dos Direitos da Criança e do Adolescente (CONANDA) e Conselho Nacional de Assistência Social (CNAS) - aparece como uma estratégia para assegurar esse direito previsto por lei, propondo o acolhimento familiar como uma das ações de proteção à infância e juventude a ser implantada em conjunto com o reordenamento do acolhimento institucional, que deve se adequar ao ECA.

O Plano Nacional ressalta a necessidade de se pensar alternativas para garantir a convivência familiar e comunitária quando o afastamento temporário da família de origem for inevitável e o acolhimento pela família extensa também não for possível. A colocação da criança ou adolescente em família acolhedora aparece como uma opção para se evitar a institucionalização e uma forma de se propiciar vivência em família, sem afastamento definitivo da criança de sua família de origem. Além disso, a inclusão do acolhimento familiar dentro da agenda de políticas públicas propostas pelas novas diretrizes nacionais, resulta em modificações nos encaminhamentos para atender às demandas de proteção de crianças e adolescentes, ampliando o sistema de medidas disponíveis de atendimento e diversificando as formas de acolhimento à infância e juventude, sendo assim mais uma opção dentro do leque de modalidades presentes na rede de proteção. Os resultados e o impacto da ampliação e qualificação dos serviços de proteção ainda não podem ser avaliados, por se encontrarem em fase de implantação no território nacional, mas certamente trarão melhorias na garantia de direitos e na qualidade de vida de seus usuários.

De acordo com as diretrizes apresentadas, $\mathrm{o}$ acolhimento familiar se propõe a atender crianças e adolescentes em situação de vulnerabilidade social ou violência doméstica, que têm seus direitos violados (Gomes, 2004). À família acolhedora são concedidas a guarda provisória e a responsabilidade pela criança acolhida, tendo para com ela todos os deveres de guardião. Essa família deve ser voluntária no processo de acolhimento, ser selecionada e receber treinamento prévio (Enout, 2004). Além disso, o caráter provisório tem como objetivo a reintegração à família de origem. Durante o acolhimento, o programa deve propor o acompanhamento da criança, da família de origem e da família acolhedora, para que os problemas existentes sejam discutidos e solucionados, possibilitando o retorno da criança ao lar de origem e assegurando ao máximo seu bem-estar.

Para possibilitar a seleção e capacitação das famílias acolhedoras, acompanhamento dos principais envolvidos e avaliação do serviço, é necessária uma equipe interdisciplinar 
atuante durante o acolhimento e no período de desligamento da criança. Vale ressaltar, que nem todos os programas são organizados dessa maneira, diferindo entre si na forma como funcionam, alguns não fazendo acompanhamento das famílias de origem e nem dos envolvidos após a separação da criança da família acolhedora (Costa \& Rossetti-Ferreira, 2009a).

Existem, portanto, normas nacionais e internacionais que preveem, quando esgotados todos os recursos para a permanência da criança na família de origem, que se deva considerar a possibilidade de colocá-la em uma família substituta, privilegiando modelos alternativos de acolhimento. A formulação de políticas nacionais e o aparecimento de documentos oficiais repensando práticas que atendam às demandas e necessidades relativas à infância e adolescência em vulnerabilidade, mostram que este é um momento propício para se discutir e investigar o acolhimento familiar como mais uma alternativa de amparo àqueles que estão privados de cuidados parentais.

Dessa forma, o objetivo deste artigo é caracterizar um programa de acolhimento familiar em andamento, visando conhecer seus principais atores (famílias acolhedoras, famílias de origem e acolhidos) e alguns dados dos acolhimentos. Considera-se relevante a investigação das experiências de acolhimento familiar já existentes, para um maior conhecimento do estado atual dessa proposta de atenção à infância e juventude em vulnerabilidade.

\section{Método}

\section{Participante}

Dentre os programas em andamento no país, foi escolhido para a pesquisa como participante focal um programa que possui considerável trajetória na área de acolhimento familiar, tendo efetuado 314 colocações de crianças e/ou adolescentes em famílias acolhedoras durante seus dez anos de funcionamento.

A coordenação do programa está a cargo da Secretaria Municipal de Assistência Social e da equipe técnica do Poder Judiciário, composta por psicólogas e assistentes sociais do Setor de Serviço Social e Psicologia da Vara da Infância e Juventude.

A equipe técnica destinada a atender o programa é formada por quatro profissionais, que organizam a divulgação do programa para a captação das famílias, utilizando-se de diversos recursos como cartazes, palestras e imprensa local. A equipe atua na inscrição e na seleção das famílias candidatas por meio de entrevistas, não havendo a proposta de capacitação das mesmas. Faz o acompanhamento das famílias acolhedoras com reuniões de grupos, entrevistas individuais e visitas domiciliares. Com as famílias de origem, atua nos momentos de ingresso e desligamento das crianças e adolescentes acolhidos, e realiza, se necessário, encaminhamentos dos membros da família de origem para os serviços da rede municipal, como serviços na área da saúde e de suporte social. Acompanha as crianças e adolescentes acolhidos através das mesmas visitas domiciliares feitas à casa da família acolhedora.

\section{Considerações éticas}

Respeitados os procedimentos éticos, o programa participante foi contatado, sendo seus coordenadores esclarecidos sobre os objetivos da pesquisa e os procedimentos que seriam utilizados. Mediante autorização do Juiz da Vara de Infância e Juventude da Comarca onde o programa é desenvolvido, foi possível o acesso aos seus registros. O estudo foi aprovado pelo Comitê de Ética em Pesquisa da Faculdade de Filosofia, Ciências e Letras de Ribeirão Preto da Universidade de São Paulo (protocolo n ${ }^{\circ} 342 / 2007$ ).

\section{Procedimentos}

\section{Coleta de dados}

Por meio de consulta a pastas, fichas e tabelas, que contêm informações do período de 1998 a 2007, foi possível levantar dados sobre os integrantes cadastrados no programa e sobre os acolhimentos efetuados. O levantamento foi tabulado dentro do Microsoft Office Access, a partir do qual foram construídas novas planilhas de registros e tabelas. Nessas, constam os desdobramentos dos acolhimentos efetuados no período e as principais características dos três grupos envolvidos: famílias acolhedoras, famílias de origem e crianças/ adolescentes acolhidos.

Assim, foi possível organizar os seguintes indicadores relativos aos grupos citados: a) idade, sexo e etnia dos acolhidos, b) idade, estado civil, escolaridade, profissão, renda, composição familiar (número de filhos) e motivação para o acolhimento das famílias acolhedoras, c) registrar a ausência de informações registradas sobre a família de origem. Além disso, também foram levantadas as causas que levaram ao acolhimento, o tempo de permanência dos acolhidos com as famílias acolhedoras (tempo de acolhimento) e os encaminhamentos efetuados pós-acolhimento (reintegração familiar, adoção, entre outros).

\section{Análise dos dados}

Os dados do corpus empírico passaram por uma análise estatística descritiva, os quais são apresentados e discutidos a seguir cotejando com resultados de outros estudos nacionais e internacionais produzidos na área. Dessa forma, a apresentação de resultados e discussão está organizada nos seguintes itens: Crianças e adolescentes acolhidos, Famílias acolhedoras, Famílias de origem e acolhimentos. Vale ressaltar que os indicadores apresentados nestes itens são aqueles que estavam disponíveis nas pastas, fichas e tabelas de registros disponibilizados pelo programa para consulta, ou seja, eles não foram definidos a priori pelas pesquisadoras. 


\section{Resultados e Discussão}

\section{Crianças e adolescentes acolhidos}

O total de 300 crianças e adolescentes acolhidos, entre 1998 e 2007 , se distribuiu em $51,7 \%$ do sexo masculino e $48,3 \%$ do sexo feminino. Quanto à faixa etária, apresentada na Figura 1, a maioria dos acolhidos encontrava-se entre zero e seis anos $(58,7 \%)$. Dentro deste grupo é grande a porcentagem de crianças de zero a três anos de idade (42\%) e daquelas que são acolhidas no primeiro ano de vida $(29,3 \%)$, mostrando que este programa de acolhimento familiar atende uma considerável parcela de bebês. Vale pontuar que é prática da rede de proteção local o encaminhamento dos bebês afastados do convívio familiar, preferencialmente, para o programa de família acolhedora.

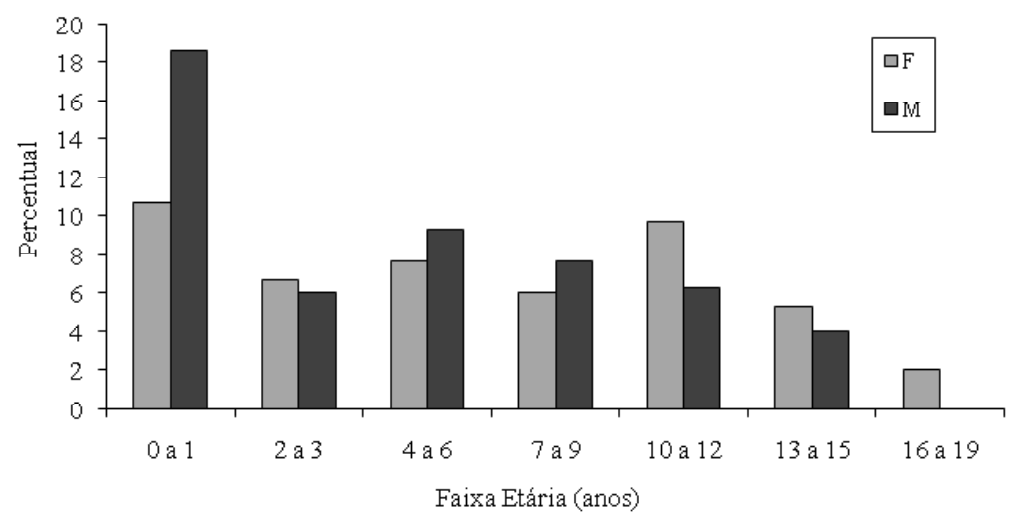

Figura 1. Porcentagem dos acolhidos por faixa etária e por sexo no período de 1998 a 2007.

A maior incidência de acolhimentos nesta faixa etária é compatível com resultados de outros estudos na área de acolhimento familiar, que apresentam altas frequências de colocação de crianças menores de seis anos ou com até um ano de idade (Rodger, Cummings, \& Leschied, 2006; Cole, 2005). Para Herce, Achucarro, Gorostiaga, Cadiz e Balluerka (2003), a idade é considerada um aspecto facilitador de integração ao acolhimento, sendo que os autores apontam que há uma maior integração quando o processo é iniciado antes dos sete anos.

Embora em frequência menor, é interessante observar que também ocorreu o acolhimento de adolescentes $(11,3 \%)$, o que demonstra que o programa atende uma população com idades bem diversificadas. Pôde-se ainda perceber, a existência de uma diferença relativa ao gênero no acolhimento, sendo o sexo feminino mais incidente. Tal experiência de colocação de adolescentes difere daquela de outros programas nacionais, não sendo uma prática comum o encaminhamento dessa faixa etária para famílias acolhedoras. As equipes dos programas relatam a dificuldade de terem famílias que se disponibilizem a acolher adolescentes, faixa etária que é temida por muitos acolhedores (Costa \& Rossetti-Ferreira, 2009a, 2009b).

A distribuição da etnia, como mostra a Figura 2, aponta para uma incidência maior de crianças brancas $(43,7 \%)$, seguidas por pardas $(30,3 \%)$ e negras $(25 \%)$. Entretanto, se considerarmos que as crianças pardas e negras podem ser classificadas como afrodescendentes, há então a predominância de crianças dessa categoria, totalizando 55,3\%. A maior frequência de crianças afrodescendentes $(87 \%)$, seguidas por brancas (13\%), também aparece em Cole (2005) sobre 46 acolhidos nos Estados Unidos.

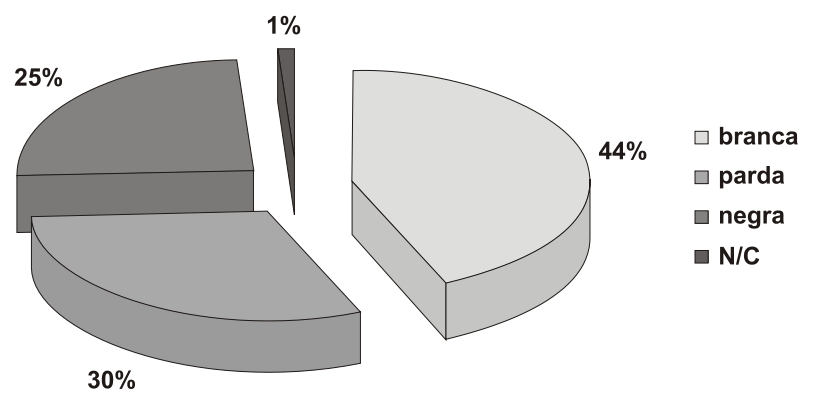

Figura 2. Porcentagem dos acolhidos no período de 1998 a 2007, segundo a etnia. 
Além do levantamento dessas características dos acolhidos, foi possível agrupar algumas características das crianças ou adolescentes que as famílias acolhedoras apontaram como de sua preferência para acolhimento, nas entrevistas iniciais realizadas pela equipe técnica para seleção dos acolhedores. Semelhante ao processo de cadastro para adoção, quando uma família inscreve-se para ser acolhedora lhe é perguntado em entrevista: “quais crianças seria capaz de acolher?”. Esse levantamento indicou uma preferência por crianças na faixa etária de zero a seis anos (37,5\%), não havendo distinção quanto ao sexo em $77,3 \%$ dos casos, que aceitavam acolher ambos, seguidos de 14,7\% que receberiam crianças somente do sexo feminino e $8 \%$ apenas do sexo masculino.

Quanto à etnia, 38,6\% dos acolhedores responderam ser indiferente, devendo-se destacar que em 56,8\% dos casos essa informação não estava registrada. Isso pode indicar que essa característica não é muito investigada pela equipe no momento de seleção da família, ou que fica subentendida a indiferença por parte dos acolhedores referente à cor da pele das crianças/adolescentes que serão por eles acolhidos. No entanto, acreditamos que esse seja um aspecto a ser melhor investigado pela equipe.

Um ponto interessante é que 18,2\% dos acolhedores concordaram em receber crianças que apresentassem problemas de saúde. Além desses, outros 17,1\% aceitaram serem consultados caso haja a necessidade de acolhimento de crianças com problemas de saúde menos severos, o que condiz com o tipo de programa que atende, em sua maioria, crianças vitimizadas ou violadas. Quando há casos de crianças/adolescentes que apresentam algum tipo de problema de saúde, a família acolhedora é sempre consultada.

Outra informação que merece ser destacada é que 23,9\% das famílias aceitaram acolher grupos de irmãos ou mais de uma criança por vez no mesmo período de acolhimento. Quanto ao tempo de permanência na família, 40,9\% se dispõem a acolher sem restringi-lo, sendo o tempo de acolhimento indeterminado. Sobre este aspecto, a opção pelo período de permanência dos acolhidos com a família acolhedora não foi registrado em 56,8\% dos cadastros, tendo sido esclarecido pela própria equipe, que também nestes casos as famílias se dispuseram a acolher por tempo indeterminado, mas a informação não foi registrada.

Se comparados o perfil das crianças pretendidas para o acolhimento com o perfil das crianças que demandam o programa, parece haver uma compatibilidade entre ambos. No entanto, essa comparação merece ser analisada com cautela, pois o número de crianças que ingressa na rede de proteção supera o de famílias acolhedoras, sendo necessárias outras formas de acolhimento e proteção para suprir a demanda. Pode-se pensar que as crianças encaminhadas ao acolhimento familiar são exatamente aquelas que atendem ao perfil pretendido pela família acolhedora - faixa etária, sexo, grupos de irmãos ou não -, e que as crianças mais velhas permanecem em outras modalidades de acolhimento, como o institucional, casas lar ou repúblicas.

\section{Famílias acolhedoras}

As 88 famílias acolhedoras cadastradas no programa ao longo do período considerado são constituídas por 70 homens e 88 mulheres. Sobre elas foi possível levantar idade, estado civil, escolaridade, profissão, renda, composição familiar e motivação para o acolhimento. Atualmente, 23 famílias acolhedoras estão cadastradas no programa, das quais 15 estão em acolhimento.

Dentre as 88 famílias acolhedoras, existem diferentes composições familiares que estão relacionadas ao estado civil de seus integrantes. Assim, encontrou-se que 70,4\% das famílias são compostas por casais e $22,78 \%$ por famílias monoparentais $(9,09 \%$ correspondem à mulher solteira; $6,82 \%$ mulher separada; $3,41 \%$ mulher viúva; $2,30 \%$ mulher divorciada e $1,16 \%$ homem solteiro), sendo que em $6,82 \%$ dos casos essa informação não consta.

Além disso, foi possível observar que as famílias geralmente têm filhos $(84,1 \%)$, sendo esses ativos parceiros em tal prática, ao concordarem em participar do programa e acolher. Segundo Spears e Cross (2003), a decisão de acolher deve ser partilhada por todos os membros da família, sendo que o envolvimento das crianças e adolescentes que acolhem pode ocasionar o sucesso ou o fracasso da colocação. A configuração de famílias acolhedoras formadas por casais com filhos é frequente em outros programas investigados (Cole, 2005; Rodger e cols., 2006).

A maioria dos adultos acolhedores encontra-se na faixa etária de 30 a 49 anos. Estudos que apresentam características etárias dos acolhedores confirmam esse intervalo, que varia de 30 a 55 anos, aproximadamente (Cole, 2005; Höjer, 2004; Rodger e cols., 2006). Vale ressaltar que essa faixa etária também é mais incidente entre casais que realizam adoções, conforme apontado nos estudos de Andrade, Costa e Rossetti-Ferreira (2006), Cassin (2000) e Weber (2003) e Mariano e Rossetti-Ferreira (2007).

Quanto ao grau de escolaridade, o mais frequente entre as mulheres foi o ensino fundamental incompleto $(27,3 \%)$, seguido pelo ensino médio completo $(22,7 \%)$. Já entre os homens o ensino superior completo $(20 \%)$ foi o mais incidente, no entanto, a informação relativa à escolaridade dos homens foi pouco registrada, pois em $32,86 \%$ dos casos ela não consta. O nível de escolarização dos integrantes das famílias acolhedoras é bastante heterogêneo, sendo diversificado inclusive dentro de cada grupo por sexo. Rodger e cols. (2006) ao relatarem dados sobre 643 acolhedores dos Estados Unidos e Canadá, observaram que esses também apresentavam um bom nível de escolarização, sendo que mais da metade tinha formação acima do Ensino Médio.

As profissões dos acolhedores são majoritariamente relacionadas a atividades autônomas em ambos os grupos masculino e feminino, devendo-se destacar o elevado número de mulheres que se dedicam a atividades domésticas (34,04\%). O fato de muitas mulheres serem classificadas como "do lar", indica uma disponibilidade por parte das mesmas em realizar 
o acolhimento e oferecer dedicação quase integral ao cuidado das crianças ou adolescentes acolhidos. A disponibilidade de tempo dos acolhedores é um dos critérios do programa na seleção dos mesmos. Höjer (2004), na Suécia, expõe resultados semelhantes mostrando que de uma amostra de 189 mães acolhedoras, 20\% trabalhavam em casa e se dedicavam exclusivamente ao cuidado das crianças acolhidas e $16 \%$ trabalhavam apenas meio período. Cole (2005), nos Estados Unidos, também relata que 56,5\% não trabalhavam fora de casa, dentro de uma amostra de 46 acolhedores.

Foi possível qualificar as profissões dos acolhedores segundo o nível de escolaridade exigido para o desempenho de cada uma delas e distribuí-las nas seguintes categorias: trabalho que não necessita de escolaridade, trabalho que exige nível primário (ensino fundamental), nível secundário (ensino médio) e nível terciário (ensino superior). O trabalho que exige nível primário foi o mais incidente, tanto no grupo de mulheres $(30,7 \%)$ quanto no de homens $(44,3 \%)$.

Outro aspecto a se considerar ainda relativo à "profissão", é que em $27,14 \%$ dos casos não consta registrada a atividade exercida pelos homens. Apesar do programa investigar qual é a profissão exercida pelos pais acolhedores, essa informação nem sempre é registrada. Parece haver um foco maior nas atividades desenvolvidas pelas mulheres, porque elas estão mais diretamente ligadas aos cuidados com os acolhidos, embora haja o envolvimento dos homens no processo de acolhimento. Eles parecem concordar em acolher e participar da proposta, mas as mulheres acabam por protagonizar a procura pelo programa, sendo mais ativas nas diferentes etapas do cadastramento, seleção e acompanhamento dos acolhidos, o que pode justificar sua maior presença nos registros do programa.

Em relação à renda das famílias, essa informação não consta em 44,32\% das famílias e ainda não há uniformidade na forma como este dado é registrado nos cadastros (renda bruta ou salários mínimos). Foi possível identificar uma grande variação quanto à situação financeira das famílias acolhedoras, havendo famílias que recebem menos de dois salários mínimos e outras mais de vinte, como pode ser visualizada na Tabela 1.

Tabela 1

Frequência e porcentagem dos integrantes das famílias acolhedoras conforme a renda familiar

\begin{tabular}{lcc}
\hline \multicolumn{1}{c}{ Renda (Salários Mínimos) } & n & $\mathbf{\%}$ \\
\hline até 1,9 & 4 & 4,54 \\
de 2,0 a 4,9 & 10 & 11,40 \\
de 5,0 a 9,9 & 14 & 15,90 \\
de 10,0 a 14,9 & 7 & 7,90 \\
de 15,0 a 19,9 & 4 & 4,54 \\
20,0 ou mais & 10 & 11,40 \\
N/C & 39 & 44,32 \\
Total & 88 & 100 \\
\hline
\end{tabular}

O não registro desta informação indica que a renda não é um critério decisivo para realizar o acolhimento, não se configurando como empecilho para efetivar a prática, pois uma boa parcela dos acolhedores possui uma faixa salarial considerada modesta. Isso mostra que o acolhimento familiar nesta cidade se configura como uma prática realizada principalmente entre pessoas de camadas populares, formando uma rede solidária (Sarti, 1996). Vale destacar que as famílias acolhedoras são voluntárias no processo, recebendo do programa o auxílio de uma bolsa por criança acolhida, proporcional ao tempo de acolhimento.

A motivação dos acolhedores para buscar o programa foi uma informação pouco registrada nas fichas às quais tivemos acesso, embora seja investigada pela equipe técnica no momento de cadastro e de seleção das famílias acolhedoras, e constem redigidas nos processos relativos a cada acolhido. Foi possível levantar apenas 18,2\% de registro da motivação para acolher, sendo que os principais motivos relacionam-se ao desejo de ser solidário, prestando auxílio a crianças/adolescentes em vulnerabilidade. Há referência também sobre motivações assistenciais, caritativas e de desejo de adoção. Existem famílias que inicialmente têm o intuito de adotar e, ao serem esclarecidas sobre a finalidade do programa, permanecem acolhendo ou são orientadas a buscar o cadastro de adoção. As principais motivações apontadas em pesquisas no campo de acolhimento familiar são compatíveis às encontradas neste estudo, sendo elas relacionadas com: motivos solidários, desejo de oferecer proteção a crianças em risco (abusadas e negligenciadas) e preocupação social (Cole, 2005; Herce e cols., 2003; Rodger e cols., 2006).

Algumas famílias justificam sua motivação para integrar o programa por terem conhecimento dele através do convívio com outras famílias acolhedoras já participantes (4,54\%). Rodger e cols. (2006) apontam também a referência de conhecimento de outras famílias acolhedoras como motivo para integrar um programa de acolhimento familiar. Este ponto merece destaque, pois indica a importância de divulgação da proposta para seleção e captação de novas famílias.

Consideramos que conhecer a motivação dos candidatos ao acolhimento é fundamental para avaliar a disponibilidade, inclusive afetiva, e o desejo dessas famílias em participar e desempenhar a função de acolher crianças/ adolescentes que se encontram em situações complexas de vulnerabilidade e vitimização.

É relevante pontuar a presença de irregularidades no modo de registro e ausência de algumas informações sobre os acolhedores. Tais problemas devem-se ao fato de que nos primeiros anos do programa muitos eventos não eram registrados, pois a colocação em famílias acolhedoras acontecia de maneira informal, em resposta a situações emergenciais. Com o passar dos anos, o programa foi se organizando e o registro das informações se tornou mais uniforme, seguindo critérios pré-definidos. 


\section{Famílias de origem}

Sobre as famílias de origem não foram encontradas informações registradas. Há uma grande disparidade entre o volume de informações disponíveis sobre as famílias acolhedoras e a ausência de dados sobre as de origem. Semelhante situação de ausência de registro também foi apontada em pesquisas sobre acolhimento institucional e adoção, nos quais também não consta um sistema de registro de informações sobre as crianças e suas famílias de maneira interligada e articulada (Mariano \& Rossetti-Ferreira, 2007; Serrano, 2008). Pode-se pensar que a falta de registros deva-se ao fato de não haver inicialmente uma proposta do programa de realizar um trabalho voltado para essas famílias, que eram encaminhadas à rede de serviços municipais, especialmente aqueles vinculados à saúde, à educação e à promoção social. Era, então, de competência da equipe técnica realizar o acompanhamento da criança e/ou adolescente acolhido e das famílias acolhedoras durante o processo de acolhimento, sendo que não efetuava ainda as visitas entre os acolhidos e suas respectivas famílias.

Segundo Sarti (1996), o desconhecimento dos limites, possibilidades e necessidades das famílias pobres - origem das crianças que ingressam na rede de proteção - inviabiliza o desenvolvimento de um trabalho que promova a solução, senão melhora, dos problemas vivenciados por elas. Dessa forma, é necessário conhecer essas famílias em seus aspectos dinâmicos, o seu universo simbólico e as questões concretas que as afetam. Tal desconhecimento também se reflete na elaboração de ações de governo e programas sociais que, por muitas vezes, não realizam um trabalho integrado e dirigido à problemática destas famílias, visando o beneficiamento das mesmas.

Segundo as novas diretrizes do Plano Nacional (Ministério do Desenvolvimento Social e Combate à Fome, 2006) e das Orientações Técnicas para os Serviços de Acolhimento de Crianças e Adolescentes (Conselho Nacional dos Direitos da Criança e do Adolescente [CONANDA], 2008), os programas de acolhimento familiar deverão considerar as famílias de origem em seu campo de atuação e intervenção, efetivando um trabalho que abranja todos os envolvidos e necessitados de suporte.

\section{Acolhimentos}

Sobre os acolhimentos efetuados no período em questão (1998-2007), foi possível levantar alguns elementos tais como: as causas que levaram à retirada da criança da família de origem e a seu acolhimento, o tempo de permanência dos acolhidos com as famílias acolhedoras (tempo de acolhimento) e os encaminhamentos efetuados pós-acolhimento.

A Tabela 2 explicita os principais motivos que fundamentaram a retirada da criança da família de origem e o consequente ingresso no acolhimento: negligência (33,7\%), abandono (22,7\%), alcoolismo/dependência química dos pais $(13 \%)$ e violência doméstica $(9,7 \%)$, o que inclui violência física, psicológica e sexual. Segundo Guerra (1985), a violência que os pais podem exercer contra os filhos assume três facetas principais: a violência física, que compreende maus-tratos corporais ou negligência relativa a cuidados básicos (alimentação, vestuário, segurança e outros); a violência sexual, quando a coação exercida visa obter a participação em práticas eróticas; e a violência psicológica, sendo a coação feita através de ameaças, humilhações ou privação emocional.

Tabela 2

Frequência e porcentagem dos motivos que fundamentaram a retirada da criança/adolescente da família de origem

\begin{tabular}{lcc}
\hline \multicolumn{1}{c}{ Motivo } & n & \% \\
\hline Negligência & 101 & 33,7 \\
Abandono & 68 & 22,7 \\
Alcoolismo/dependência química dos pais & 39 & 13,0 \\
Violência doméstica & 29 & 9,7 \\
Conflito familiar & 27 & 9,0 \\
Pais presidiários/ausência dos pais & 11 & 3,6 \\
Doença mental familiar & 7 & 2,3 \\
Orfandade & 6 & 2,0 \\
N/C & 12 & 4,0 \\
Total & 300 & 100 \\
\hline
\end{tabular}

É importante pontuar que os motivos encontrados para retirada da criança de sua família de origem e entrada no acolhimento familiar são os mesmos apontados em pesquisas que enfocam o acolhimento institucional (Serrano, 2008; Silva, 2004). A negligência, referida em $33,7 \%$ dos casos do programa acompanhado, nos parece uma categoria de difícil definição, pois os critérios adotados pelos técnicos ao considerá-la como motivo para a retirada ficam encobertos ou pouco evidentes, podendo englobar situações muito variadas.

$\mathrm{O}$ conceito de negligência familiar abarca diferentes tipos de violência, sendo o abandono e a omissão de cuidados os mais frequentes. A negligência pode ser entendida como uma falha na provisão de cuidados básicos, pela família ou sociedade, em circunstâncias nas quais tais cuidados poderiam ser oferecidos (Bazon, 2008; Costa, 2007; Silva \& Ferriani, 2007). Serrano (2008) argumenta que a pobreza e as dificuldades socioeconômicas contribuem no provimento insuficiente das necessidades da criança pelas famílias, e ressalta a importância de ações de Estado para garantir suporte social a essas famílias, sendo ele também responsável por atender as demandas das crianças.

Se considerarmos como Bazon (2008), que a violência doméstica engloba além das violências física, sexual e psicológica, também a categoria de negligência e abandono, podese ponderar que essa é a principal causa relatada no programa 
estudado relativa à retirada de crianças/adolescentes de suas respectivas famílias e a consequente entrada dos mesmos na rede de proteção. Dos acolhimentos registrados, 198 casos podem ser caracterizados como violência doméstica, ou seja, $66 \%$ do total. Sabe-se, no entanto, que as diferentes categorias estão interligadas e associadas, não sendo apenas um motivo o responsável pela colocação em família acolhedora, o que demonstra que a problemática enfrentada pelas famílias de origem é bastante complexa. Assim, em um mesmo caso foram citadas mais de uma causa para o acolhimento.

Quanto ao tempo de acolhimento, o período de maior incidência foi o de um a seis meses, ocorrido em 46,65\% dos casos. Há acolhimentos que duram apenas alguns dias (12,3\%), o que nos leva a refletir se realmente foram esgotadas todas as possibilidades antes da aplicação dessa medida de proteção. Também ocorreram acolhimentos mais longos, compreendidos num período de sete a onze meses $(11,36 \%)$ e ainda aqueles de um ano ou mais (7\%). Em 22,7\% dos acolhimentos essa informação não consta, sendo casos antigos em que não houve o registro, ou situações em que a criança ou adolescente foi adotada ou permanece com a família acolhedora.

É importante considerar que o período de acolhimento incluiu o tempo demandado para que ocorram todos os trâmites legais, como a expedição de guarda, o contato com as famílias acolhedoras e a passagem por todas as instâncias envolvidas no processo de acolhimento, o que envolve o Ministério Público, o Poder Judiciário, o Conselho Tutelar. Além disso, posteriormente, para que ocorra o "desacolhimento", existem também etapas que interferem no andamento do processo e na permanência da criança/adolescente com as famílias acolhedoras. Os trâmites legais e as etapas são alguns dos fatores determinantes que compõem o tempo do acolhimento.

Quanto aos encaminhamentos pós-acolhimento, foi possível levantar que: $34,2 \%$ das crianças foram adotadas; $33,8 \%$ foram reintegradas às suas famílias; $12,1 \%$ voltaram para abrigos; 3,91\% seguiram vida independente (adolescentes desacolhidos); 4,61\% ficaram sob tutela ou guarda das famílias acolhedoras; e 1,42\% foram para uma instituição (berçário) que presta atendimento a crianças doentes ou convalescentes, conforme mostra a Tabela 3. No mês de férias dessa instituição, as crianças que não têm como retornar às suas respectivas famílias de origem são encaminhadas pelo Judiciário ou Conselho Tutelar ao programa de famílias acolhedoras. Em alguns casos, o berçário acaba funcionando como abrigo (medida de proteção).

Dentre as crianças que foram destinadas à adoção (34,2\%), 9,6\% foram adotadas pelas próprias famílias acolhedoras e houve um caso de adoção por familiares da criança acolhida. A alta incidência de adotados após o período de acolhimento evidencia a dificuldade deste programa em realizar a reintegração familiar, isto é, o retorno da criança/ adolescente ao seu lar de origem, meta principal da medida de acolhimento familiar. Entretanto, deve-se ressaltar que esse não era um objetivo do programa até bem recentemente. O foco de sua ação residia no acolhimento e na garantia de convivência familiar e comunitária. Somente a partir desse ano iniciou-se um trabalho de acompanhamento da família de origem, o que evidencia um esforço de reordenamento do programa segundo os novos parâmetros nacionais para funcionamento do acolhimento familiar (CONANDA, 2008; MDS, 2006).

Tabela 3

Frequência e porcentagem dos encaminhamentos das crianças/adolescentes pós-acolhimento no período de 1998 a 2007

\begin{tabular}{lcc}
\hline \multicolumn{1}{c}{ Encaminhamentos } & n & \% \\
\hline Adoção & 96 & 34,20 \\
Reintegração familiar & 95 & 33,80 \\
Abrigos & 34 & 12,10 \\
Vida independente & 11 & 3,91 \\
Tutela Família Acolhedora & 10 & 3,55 \\
Instituição (berçário) & 4 & 1,42 \\
Guarda Família Acolhedora & 3 & 1,06 \\
N/C & 28 & 9,96 \\
Total & 281 & 100 \\
\hline
\end{tabular}

No que se refere à reintegração familiar, essa pode ocorrer em um núcleo familiar diferente do qual a criança foi retirada, configurando ações da rede de parentesco mais ampla, em que a criança permanece junto à família extensa constituída pelos familiares (avós, tios, irmãos) ou outros adultos próximos, dentro do grupo de referência dos pais.

Um ponto a se considerar é que alguns dos acolhidos são reincidentes e podem passar por diferentes famílias acolhedoras, ou pelo abrigo. Os encaminhamentos para os abrigos apontam o importante papel destas instituições na rede de proteção, mostrando que o acolhimento familiar é uma das alternativas de acolhimento e não uma medida substituta às instituições, que devem atender os critérios de qualidade e reordenamento de suas ações. Além dos abrigos, também é de fundamental importância o papel exercido por toda a rede de proteção, composta pelos serviços de promoção social, justiça, saúde, educação e outros atores envolvidos.

\section{Considerações finais}

O acolhimento familiar se configura como uma nova modalidade de proteção e de organização familiar que suscita questões pertinentes a um campo bastante amplo e multidisciplinar. A implementação de ações de governo, como os programas de famílias acolhedoras, ocorre simultaneamente ao reordenamento do acolhimento institucional e familiar em âmbito nacional, como preveem atuais diretrizes e normativas. 
Sobre os dados apresentados neste artigo, como são relativos aos dez anos de execução do programa, pode-se afirmar que em sua maior parte se referem a um período anterior às normativas e ao reordenamento, período em que já funcionavam alguns programas de acolhimento familiar no Brasil. Contudo, o presente estudo já sinaliza alguns grandes desafios a serem enfrentados por esse programa na tentativa de cumprir as novas diretrizes legais. Um deles diz respeito à ausência de informações sobre as famílias de origem, o que reflete a não realização do trabalho de acompanhamento das mesmas pela equipe técnica do programa. A família de origem é um dos vértices de atuação do acolhimento familiar e deverá merecer um investimento técnico significativo das equipes dos programas para que se possa alcançar o objetivo da medida protetiva, que é a reintegração familiar. Dessa forma, os encaminhamentos pós-acolhimento que tiveram maior incidência para adoção, talvez possam ser modificados, permitindo que as crianças voltem à convivência familiar em suas próprias famílias e não em famílias substitutas.

Outro desafio constitui o enfrentamento dos fatores causais da retirada da criança ou adolescente de sua família, onde a negligência se destaca como motivo preponderante. A negligência muitas vezes é significada como um mau trato da família, trazendo consigo uma culpabilização das famílias de origem pelas deficiências na provisão de cuidados básicos às crianças, sem considerar a insuficiência ou inexistência de apoio social e políticas públicas para essa parcela da população. É importante considerar que as desigualdades sociais contribuem para o provimento insatisfatório de necessidades das crianças. Os altos índices de negligência em serviços de acolhimento podem indicar a importância de políticas públicas e disponibilização de suporte pelo Estado para assegurar condições de convivência doméstica adequadas às famílias. Assim, as ações governamentais e a família são responsáveis por atender as necessidades da criança, desmistificando a ótica da família pobre e culpada, sobre as quais recai a atribuição de incapacidade na dedicação de cuidados adequados aos seus filhos.

Argumenta-se então que o conhecimento do perfil dos principais atores envolvidos na medida de acolhimento familiar pode orientar ações condizentes com suas características - sociodemográficas, desenvolvimentais, necessidades e demandas, dimensões da realidade - e proporcionar resultados mais eficazes em seu atendimento. As características das famílias acolhedoras do programa investigado se assemelham muito àquelas abordadas em outros estudos nacionais e internacionais produzidos na área, indicando a mesma configuração familiar de casais com filhos, a faixa etária dos acolhedores entre 30 e 49 anos, o bom nível de escolarização, motivações solidárias e relativas à preocupação social para participação em programas de acolhimento familiar e, ainda, o longo tempo despendido pelas mães acolhedoras nos cuidados com as crianças e adolescentes acolhidos. Sobre os acolhidos, converge a maior incidência de acolhimentos de crianças de até seis anos de idade nos estudos apresentados, e a experiência de colocação de adolescentes em famílias acolhedoras do presente programa difere de outros no país.

Além do perfil das pessoas, conhecer a constituição e o modo de funcionamento dos programas é de fundamental importância, pois permite delinear como essas práticas de atenção a crianças e adolescentes em situações de vulnerabilidade estão sendo concretizadas, possibilitando que sejam sugeridas eventuais modificações na estrutura formal e práticas cotidianas, como a padronização dos registros para facilitar o trabalho dos próprios técnicos. As mudanças visam obter melhorias e benefícios para toda a população usuária dos serviços de acolhimento, inclusive as famílias de origem.

A análise dos programas de acolhimento em andamento oferece substrato para que sejam propostas intervenções em situações de grande complexidade, como as que envolvem as famílias das crianças e adolescentes acolhidos. Os encaminhamentos devem considerar as especificidades dos casos abordados, sendo o acolhimento familiar uma das medidas possíveis que compõem a rede de proteção, ao lado de outras modalidades de atendimento.

Promover estudos de aprofundamento na área é de fundamental importância, visto que o acolhimento familiar encontra-se em processo de implantação. As experiências de programas vigentes que precederam essa nova proposta de atendimento permitem a discussão da medida e reforçam a necessidade do reordenamento que vem ocorrendo em território nacional. Além disso, podem apontar a viabilidade de aplicação da medida por mostrar programas que já estão em funcionamento, inclusive com altos índices de reintegração familiar, alcançando assim seu objetivo primordial.

\section{Referências}

Amorós, P., \& Palacios, J. (2004). Acogimiento familiar. Madrid: Alianza Ensayo.

Andrade, R. P., Costa, N. R. A., \& Rossetti-Ferreira, M. C. (2006). Significações de paternidade adotiva: Um estudo de caso. Paidéia (Ribeirão Preto), 16, 241-252.

Bazon, M. R. (2008). Violências contra crianças e adolescentes: Análise de quatro anos de notificações feitas ao conselho tutelar na cidade de Ribeirão Preto, São Paulo, Brasil. Cadernos de Saúde Pública, 24, 323-332.

Brasil, E. D. (2004). O conceito de Acolhimento Familiar na ótica de diversos atores estratégicos. In C. Cabral (Org.), Acolhimento familiar: Experiências e perspectivas (pp. 102-111). Rio de Janeiro: UNICEF/Terra dos Homens/ Booklink.

Cabral, C. (2004). Perspectivas do Acolhimento Familiar no Brasil. In C. Cabral (Org.), Acolhimento familiar: Experiências e perspectivas (pp. 10-17). Rio de Janeiro: UNICEF/Terra dos Homens/ Booklink.

Cassin, W. (2000). O psicólogo judiciário e a cultura da adoção: Limites, contradições e perspectivas. Dissertação de mestrado não publicada, Universidade de São Paulo, Ribeirão Preto, SP. 
Cole, S. A. (2005). Foster caregiver motivation and infant attachment: How do reasons for fostering affect relationships? Child and Adolescent Social Work Journal, 22, 441-457.

Conselho Nacional dos Direitos da Criança e do Adolescente. Conselho Nacional de Assistência Social. (2008). Orientações técnicas para os serviços de acolhimento de crianças e adolescentes. Brasília, DF: Autores.

Organização das Nações Unidas. Assembléia Geral das Nações Unidas (1989). Convenção sobre os Direitos da Criança. Recuperado em 13 de setembro de 2010, de http://www2.ohchr.org/english/law/pdf/crc.pdf

Costa, M. C. O. (2007). O perfil da violência contra crianças e adolescentes, segundo registros de Conselhos Tutelares: Vítimas, agressores e manifestações de violência. Ciências Saúde Coletiva, 12, 1129-1141.

Costa, N. R. A., \& Rossetti-Ferreira M. C. (2009a). Familias Acolhedoras: Uma análise de experiências no estado de São Paulo. Relatório científico de pósdoutorado não publicado, Universidade de São Paulo, Ribeirão Preto, SP.

Costa N. R. A., \& Rossetti-Ferreira M. C. (2009b). Acolhimento familiar: Uma alternativa de proteção para crianças e adolescentes. Psicologia: Reflexão e Crítica, 22, 111-118.

Enout, R. (2004). A base legal dos projetos de Acolhimento Familiar. In C. Cabral (Org.), Acolhimento Familiar: Experiências e perspectivas (pp. 10-17). Rio de Janeiro: UNICEF/Terra dos Homens/ Booklink.

Fonseca, C. (1995). Caminhos da adoção. São Paulo: Cortez.

Fonseca, C. (2002). The politics of adoptions: Child rights in the Brazilian setting. Law \& Policy, 24, 199-227.

Franco, A.A. P. (2000). Sobre silêncios e palavras: Os lugares da infância e da juventude. O trabalho desenvolvido com famílias substitutas na Comarca de Franca-SP. Dissertação de mestrado não publicada, Universidade Estadual Paulista, Franca, SP.

Gomes, M. (2004). O projeto Família Acolhedora no Rio de Janeiro. In C. Cabral (Org.), Acolhimento familiar: Experiências e perspectivas (pp. 45-56). Rio de Janeiro, RJ: UNICEF/Terra dos Homens/ Booklink.

Guerra, V. N. A. (1985). Violência de pais contra filhos: Procuram-se vítimas. São Paulo: Cortez.

Herce, C., Achucarro, C., Gorostiaga, A., Cadiz, B. T. G., \& Balluerka, N. (2003). La integración del menor en la familia de acogida: Factores facilitadores. Intervención Psicosocial, 12,163-177.

Höjer, I. (2004). What happens in the foster family? A study of fostering relationships in Sweden. Adoption \& Fostering, 28(1), 38-48.

Lei No. 8.069, de 13 de julho de 1990. (1990, 13 de julho de 1990). Estatuto da Criança e do Adolescente. Brasília, DF.
Luna, M. (2004). Como melhorar e desenvolver o Acolhimento Familiar na Argentina. In C. Cabral (Org.), Acolhimento Familiar: Experiências e perspectivas (pp. 122-135). Rio de Janeiro: UNICEF/Terra dos Homens/ Booklink.

Marcílio, M. L. (1993). A irmandade da Santa Casa de Misericórdia e a assistência à criança abandonada na história do Brasil. In M. L. Marcílio (Org.), Família, mulher, sexualidade e Igreja na história do Brasil (pp. 149-156). São Paulo: Loyola.

Mariano, F. N., \& Rossetti-Ferreira, M. C. (2007). Que perfil da família biológica e adotante, e da criança revelam os processos judiciais? Psicologia: Reflexão e Crítica, 21(1), 11-19.

Martí, P. A., \& Peláez, N. F. (2004). Perspectivas y tendencias del acogimiento familiar en Cataluña. In J. Bestard, \& D. Marre (Eds.), La adopción y el acogimiento: Presente y perspectivas (pp. 173-193). Barcelona, ES: Universidade de Barcelona.

Ministério do Desenvolvimento Social e Combate à Fome. Secretaria Especial de Direitos Humanos. (2004). Política Nacional de Assistência Social. Brasília, DF: Autores.

Ministério do Desenvolvimento Social e Combate à Fome. Secretaria Especial de Direitos Humanos. (2006). Plano nacional de promoção, defesa e garantia do direito de crianças e adolescentes à convivência familiar $e$ comunitária. Brasília, DF: Autores.

Rizzini, I. (1993). Assistência à Infância no Brasil: Uma análise de sua construção. Rio de Janeiro: Ed. Universitária Santa Úrsula.

Rizzini, I., \& Rizzini I. (2004). A institucionalização de crianças no Brasil: Percurso histórico e desafios do presente. Rio de Janeiro: Ed. PUC-Rio.

Rodger, S., Cummings, A., \& Leschied A. W. (2006). Who is caring for our most vulnerable children? The motivation to foster in child welfare. Child Abuse \& Neglect, 30, 1129-1142.

Sarti, C. A. (1996). A família como espelho. Campinas, SP: Autores Associados.

Serrano, S. A. (2008). O abrigamento de crianças de 0-6 anos de idade em Ribeirão Preto: Caracterizando esse contexto. Tese de doutorado não publicada. Universidade de São Paulo, Ribeirão Preto.

Silva, E. R. A. (2004). O direito à convivência familiar $e$ comunitária: Os abrigos para crianças e adolescentes no Brasil. Brasília, DF: IPEA/CONANDA.

Silva, M. A. I., \& Ferriani, M. G. C. (2007). Domestic violence: From the visible to the invisible. Revista LatinoAmericana de Enfermagem, 15, 275-281.

Spears, W., \& Cross, M. (2003). How do Children who foster perceive fostering? Adoption \& Fostering, 27(4), 38-45.

Weber, L. N. D. (2003). Pais e filhos por adoção no Brasil. Curitiba, Juruá. 
Lara Barros Martins é mestranda em Psicologia pelo Programa de Pós-graduação em Psicologia da Faculdade de Filosofia, Ciências e Letras de Ribeirão Preto da Universidade de São Paulo.

Nina Rosa do Amaral Costa é Professora Doutora da Faculdade de Ciências Agrárias e Veterinárias da Universidade Estadual Paulista, campus Jaboticabal.

Maria Clotilde Rossetti-Ferreira é Professora Titular da Faculdade de Filosofia, Ciências e Letras de Ribeirão Preto da Universidade de São Paulo, campus Ribeirão Preto.

Recebido: 15/01/2009

$1^{a}$ revisão: 15/07/2009

$2^{a}$ revisão: 08/09/2009

Aceite final: 02/10/2010 